\title{
Choice of revegetation techniques for degraded areas using environmental damage assessment in the Amazon Forest, Brazil
}

\author{
A. I. Ribeiro ${ }^{1}$, F. H. Fengler ${ }^{1}$, R. M. Longo ${ }^{2}$, G. A. de Medeiros ${ }^{1}$, \\ G. F. Mello ${ }^{1} \&$ A. P. Filho ${ }^{3}$ \\ ${ }^{1}$ Universidade Estadual Paulista, UNESP, Brazil \\ ${ }^{2}$ Pontifical Catholic University of Campinas, Brazil \\ ${ }^{3}$ Research Campinas Agronomic Institute, Brazil
}

\begin{abstract}
The success in environmental recovery process is highly dependent on the knowledge of the characteristics of the new environment formed. Knowledge about historical degradation, activities developed, aspects and negative environmental impacts of human activity, allied with the characteristics of the new environment formed, allows the definition of effective strategies to the environmental recovery process. In this sense there is a necessity to develop more effective techniques and proposals for environmental recovery in degraded areas especially those that are located in regions with high environmental relevance, and explored by activities which promote a high degree of change in the environmental components. This paper presents a methodology for recovery of mined areas, using the assessment of environmental damage to define the recovery strategies. The work was developed in the Amazon ecosystem in a region explored by Cassiterite mining. The environmental damage was assessed in terms of the physical and biotic environment components, listed from the environmental aspects and impacts of historical exploration. Physical and chemical analyzes of degraded substrates were used to support zoning processes and to select the recovery activities. The methodology allowed identifying different degraded conditions in substrates, and determining the most affected environmental components. It was possible to define appropriate actions to recover the location, consolidating a methodology to manage degraded areas by mining and other activities with similar levels of environment alteration.

Keywords: Amazon forest, mining, recovery, soil.
\end{abstract}




\section{Introduction}

The expansion of the human population requires the conversion of natural systems to other uses, even though these are crucial sources of environmental services and are important to the survival of humanity. As an example the process of occupation of the Amazon biome can be mentioned, with the accelerated process of environment degradation and deforestation, or the mineral exploration, and unordered timber.

Accordingly, several studies have been published warning of the environmental risks that may arise from removing large portions of the Amazon primary forest. Its importance to global climate balance, global water and energy cycles show the importance of adopting actions for its preservation [1-3]. The recognition of natural areas as being important to maintain quality of life, has been a growing concern in nations, society, businesses and government agencies to environmental issues. Nowadays, the commitment in relation to environmental preservation has intensified. Thus, according to the negative responses of nature to its intensive use, there is a growing awareness that human actions on the environment must be minimized, seeking to combine the development and sustainability.

In this context the long history of mineral exploration in Brazil must be highlighted. Since the colonial period the activity has been carried out intensively. Currently Brazil is one of the greatest exploitation countries of mineral resources in the western world [4].

The world reserves of Cassiterite resources was approximately 5.6 Mt (million tons) in 2008, distributed as follows: $1^{\text {st }}-$ China (30.4\%), $2^{\text {nd }}-$ Indonesia $(14.3 \%)$, $3^{\text {rd }}-$ Peru $(12.7 \%), 4^{\text {th }}-$ Brazil $(9.4 \%), 5^{\text {th }}-$ Malaysia $(8.4 \%), 6^{\text {th }}-$ Bolivia $(8.0 \%)$, $7^{\text {th }}-$ Russia $(5.4 \%)$ and $8^{\text {th }}-$ Australia $(2.7 \%)$ [4]. It shows the significant role that Brazil has in the international trade of Cassiterite.

Therefore a vital component in the exploration of mineral resources in Brazil is the recovery and/or restoration of degraded areas. Especially in surface mining cases, an activity which has major impacts on soil and landscape. This consists in a complex task that requires different techniques and strategies, being closely related to the level of degradation of the environment, and the defined future use for the area [5].

A broad spectrum of recovery methods has emerged from the demands for projects of recovery [6]. When the given area is surrounded by large forest remnants the forest restoration has a great chance of success, even if in the beginning there were only one or a few species, because local diversity will be guaranteed by the dispersion of seeds from the adjacent forest areas.

However in cases where the area is isolated with great mischaracterization of relief, and removal of surface soil layers, it is necessary to adopt the topographic reconstruction and rebuild the soil layers, until it is possible to provide the minimum necessary conditions for the development of vegetation and the ecosystem that will inhabit the region. In other situations the environmental damage may not allow such a development, and therefore it may be necessary to assign another use to the site. 
In this sense it is crucial to understand the historical process of degradation, the history of developed activities, aspects and negative environmental impacts of human activity, and in addition to the characteristics of the new environment formed, implement effective activities for environment recovery. Thus, this work presents a methodology to recover degraded areas explored by Cassiterite mining activity, on floor tilling substrate, based on the assessment of environmental damage, developed in Amazonian ecosystem.

\section{Materials and methods}

\subsection{Characterization of the study area}

The study area is located in the National Forest of Jamari, administered by the Brazilian Institute of Environment and Renewable Mineral Resources - IBAMA, located $90 \mathrm{~km}$ from the city of Porto Velho (RO), in the municipality of Itapuã d'Oeste, with an approximate area of 225,000 ha, of which $90 \%$ of the total area is covered by open rainforest [7].

The climate is equatorial hot and humid, with average temperatures of $24^{\circ} \mathrm{C}$ and an annual rainfall of 2,550 $\mathrm{mm}$. The rain season occurs between December and March. The relative humidity is around $80 \%$ to $85 \%$ with a defined dry season between July and August.

Since the early 1960s, the Amazon region has been explored for the extraction of Cassiterite, these activities have created degraded areas whose environmental recovery has been performed.

The activities of recovery degraded areas by mining in the Jamari National Forest began in the 1990s, but given the ineffectiveness of the initial activities in 2000 , strategies based on environmental damage assessment have been developed to obtain success in the recovery process.

\subsection{Environmental damage assessment}

To assess the environmental damage we used an adaptation of the methodology used in environmental impact assessment using the evaluation matrix proposed by [8].

The environmental damage was assessed in terms of physical and biotic components of the environment, listed from the identified environmental aspects and impacts in the historical exploration of the site.

The environmental characterization was performed based on four criteria: (1) Magnitude: which refers to the dimension of the environmental damage, presenting as small (Sm), Medium (Med), and Large (L); (2) Temporality: assessing the duration of the damage. The damage may cease with the completion of the activity, characterized as temporary (T), or continue for a long time, considered permanent (Per); (3) Reversibility: indicates whether the damage is irreversible (Irr) or can return to the original state, considered to be reversible (Rev); (4) Comprehensiveness: is related to the area of influence of environmental 
damage, considered punctual (Pnt) or, if the surrounding areas are affected, regional (Reg).

The classification of environmental severity was performed to determine the influence of the environmental damage on the environmental quality. It was assigned a numerical scale to weigh the environmental damage (Table 1), and, subsequently, the environmental damage was scored using a predetermined numerical range, with values assigned according to their characteristics and their respective weights (Table 2).

Table 1: Criteria used for weighting the severity of environmental damage.

\begin{tabular}{cl}
\hline Value & Classification \\
\hline 1 & $\begin{array}{l}\text { Damage sufficiently severe, with consequences often corrected } \\
\text { naturally in the short term. }\end{array}$ \\
2 & $\begin{array}{l}\text { Damage bit severe, with the possibility of natural recovery in the } \\
\text { short to medium term. }\end{array}$ \\
3 & $\begin{array}{l}\text { Damage moderately severe, with consequences corrected in the } \\
\text { medium term, deserving greater attention by area managers. }\end{array}$ \\
4 & $\begin{array}{l}\text { Severe damage, with serious consequences in the affected region } \\
\text { and necessity of intervention by area managers. }\end{array}$ \\
& $\begin{array}{l}\text { Damage very severe, requiring urgent treatment action by area } \\
\text { managers. }\end{array}$ \\
\hline
\end{tabular}

Table 2: Values assigned to Magnitude, Temporality, Reversibility and Comprehensiveness of environmental damage and weighting values.

\begin{tabular}{lcccc}
\hline Characteristic & Weight & \multicolumn{3}{c}{ Attributed values } \\
\hline Magnitude & 5 & $\mathrm{Sm}=1$ & $\mathrm{Med}=3$ & $\mathrm{~L}=5$ \\
Temporality & 3 & $\mathrm{~T}=2$ & $\mathrm{Per}=4$ \\
Reversibility & 5 & $\mathrm{Rev}=1$ & $\mathrm{Irr}=2$ \\
Comprehensiveness & 2 & $\mathrm{Pnt}=1$ & $\mathrm{Reg}=3$ \\
\hline
\end{tabular}

The level of significance of the environmental damage was determined according to the intervals presented in Table 3 . The significance level is associated with the importance of giving environmental damage, indicating the need to prioritize those with a higher level of significance in the decision-making process. 
Table 3: Numerical scale of significance used to classify the environmental damage.

\begin{tabular}{cl}
\hline Numerical scale & Level of significance \\
\hline Smaller than 30 & $\begin{array}{l}\text { Little significant damage. No need for mitigation } \\
\text { measures with possibility of natural restoration of the } \\
\text { affected area. } \\
\text { Significant damage with fewer consequences. Need for } \\
\text { measures to control, monitor, and mitigate the damage, } \\
\text { implemented in the medium or long term. }\end{array}$ \\
Greater than 41 & $\begin{array}{l}\text { Damage very significant. Requires immediate } \\
\text { intervention. }\end{array}$ \\
\hline
\end{tabular}

\subsection{Data processing and analysis}

The analysis of degraded soil substrate particle size was conducted through the pipette method. The soil substrate density was determined using the volumetric ring, and volumetric density of particles by the method of volumetric flask, with composite samples collected from 5 to $35 \mathrm{~cm}$.

Chemical analyses were conducted in order to evaluate the conditions of the soil substrate to support the vegetation development. The $\mathrm{pH}\left(\mathrm{CaCl}_{2}\right)$, organic matter content, available phosphorus $(\mathrm{P})$, potassium $(\mathrm{K})$, calcium $(\mathrm{Ca})$, magnesium $(\mathrm{Mg})$, and extracted aluminum $(\mathrm{Al})$, cation exchange capacity $(\mathrm{T})$, and base saturation ( $\mathrm{V} \%$ ) were determined.

Field and laboratory data were organized, digitized and included in the relational database of Microsoft Access. Photographic records were also attached. The results of the environmental damage in the field and office were confronted and any discrepancies were corrected.

From the results, we have established a methodological recovery proposal for each environmental damage situation encountered.

\section{Results and discussion}

\subsection{Environmental zoning of mining areas}

The different activities and processes involved in Cassiterite mining result in substrates with characteristics that arise from the type and composition of the matrix rock, degradation processes, shape and duration of exposure to remaining material.

Due to a very wide variety of situations, the classification of the material to be recovered was made necessary to establish the required recovery approaches and the correct interpretation to the results obtained by environmental damage assessment. Figure 1 shows the zoning proposition established. 


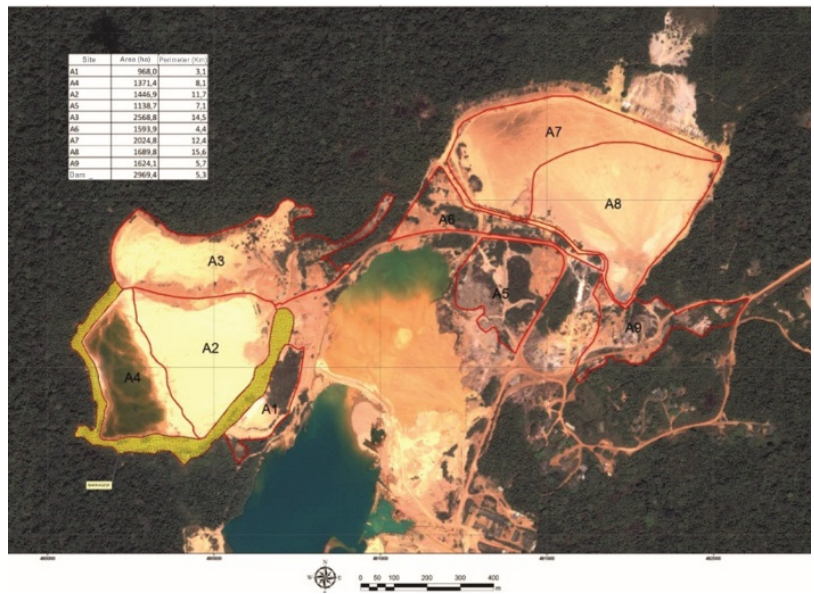

Figure 1: Environmental zoning in the mining area.

A7, A8 - pit mine: The armhole opening for exploiting Cassiterite requires exposure of the slopes and the construction of berms. The steepness of the slopes and width, traditionally, is determined according to the characteristics of the material, the process of pit opening, the need for access roads, and the volume of ore to be exploited. In turn, this volume depends on the purity of the ore and the economic aspects of the process (market value of Cassiterite, stripping ratio/ore extraction costs, discharge of water in processing, etc.). To the extent that the pit deepens, it requires greater exposure of slopes and larger area of berms.

Tailings deposition area - dry and wet: In areas of open pit, ore removal without the return of sterile or even the surface horizons (pit filling) leads to a remnant substrate formed by a heterogeneous mass of material. These areas are filled with sediment, drained or partially drained, with variable grain size, subject to flooding, causing problems in sustaining the physical terrain, making the mechanization difficult or impossible. The characteristics of this substrate depend on physical and geochemical properties of the rock that gave rise to the waste, but usually they are very poor and devoid of organic matter, and greatly hinder plant growth.

$A 2, A 3$ - reject dry: The dry reject is near to the dam of the tailings containment. It presents larger particle size, mainly sand, little or no soil structure, low or very low natural fertility and the mechanization is sometimes difficult, because the material is very loose. They also have excessive drainage capacity which makes the material with low water retention capacity.

A1, A4, A5, A6, A9-reject wet: Represents the farthest dam containment of tailings, usually near watercourses. Its particle size is very thin with predominance of clay. Due to its proximity to watercourses it may remain flooded part of the year; a prior study of the drainage is necessary for the recovery process. Trafficking machinery is very difficult because of the constant presence of excess moisture. 


\subsection{Assessment of environmental damage in mining area floor}

Table 4 shows the matrix used to assess the environmental damage in areas localized in floor tilling substrate. Damages with greater significance are linked to the physical environment. In biotic environments the most significant damages are linked to changes in forest structure and removal of native forest.

The results are consistent with the history of exploration, since the mining process produces profound changes in the landscape, with the removal of topsoil, and alteration of surface water drainage, resulting in significant damage in the physical environment.

According to [9] alternatives applied to the recovery of degraded areas can be distinguished according to the field of scientific knowledge which they are based: revegetation, geotechnology and remediation. These alternatives have the goal of physical, chemistry, and biological environment stability.

In this context, considering the analysis of environmental damage, it was decided to primarily implement the topographic reconstruction of the area and subsequently the revegetation.

\subsection{Surveying techniques for topographic reconstruction}

The topographic reconstruction is understood as the realization of simple earthworks, redesigning existing irregular topographic surfaces in newly mined areas. The activity is performed with the aid of machinery and equipment of the mine.

Even with the possibility to shape the relief, the new surfaces obtained were significantly different from the original ones.

The topographic reconstruction of degraded surfaces comprises the initial stage of the technical support for the recovery of degraded areas; either with the objective of re-establishing the vegetation or other form of use to the degraded site. In this field, the studies are still incomplete, because geological forms associated to the landscape are not able to be redone with human action.

Operations to topographic reconstruction and preparation of surfaces that were considered basic in the process of environmental recovery, and their respective sub operations are shown in Table 5.

Knowing the operations to be performed, the planning was starting for the execution of the work, setting the time and the resources needed.

\subsection{Techniques for revegetation in degraded areas}

For the construction of a new ecological system it was understood to be the revegetation of the degraded site. The success of vegetation reconstitution is highly dependent on the reconstitution of the soil, from the degraded substrate. For this purpose the operations listed below were employed.

Composting: In mined areas, soil organic matter and nutrients are low or nonexistent. The application and incorporation of some type of organic matter (litter, organic compounds, etc.) on the substrate surface proved to be very influential in the acceleration of the process of forest restoration. The compost was 


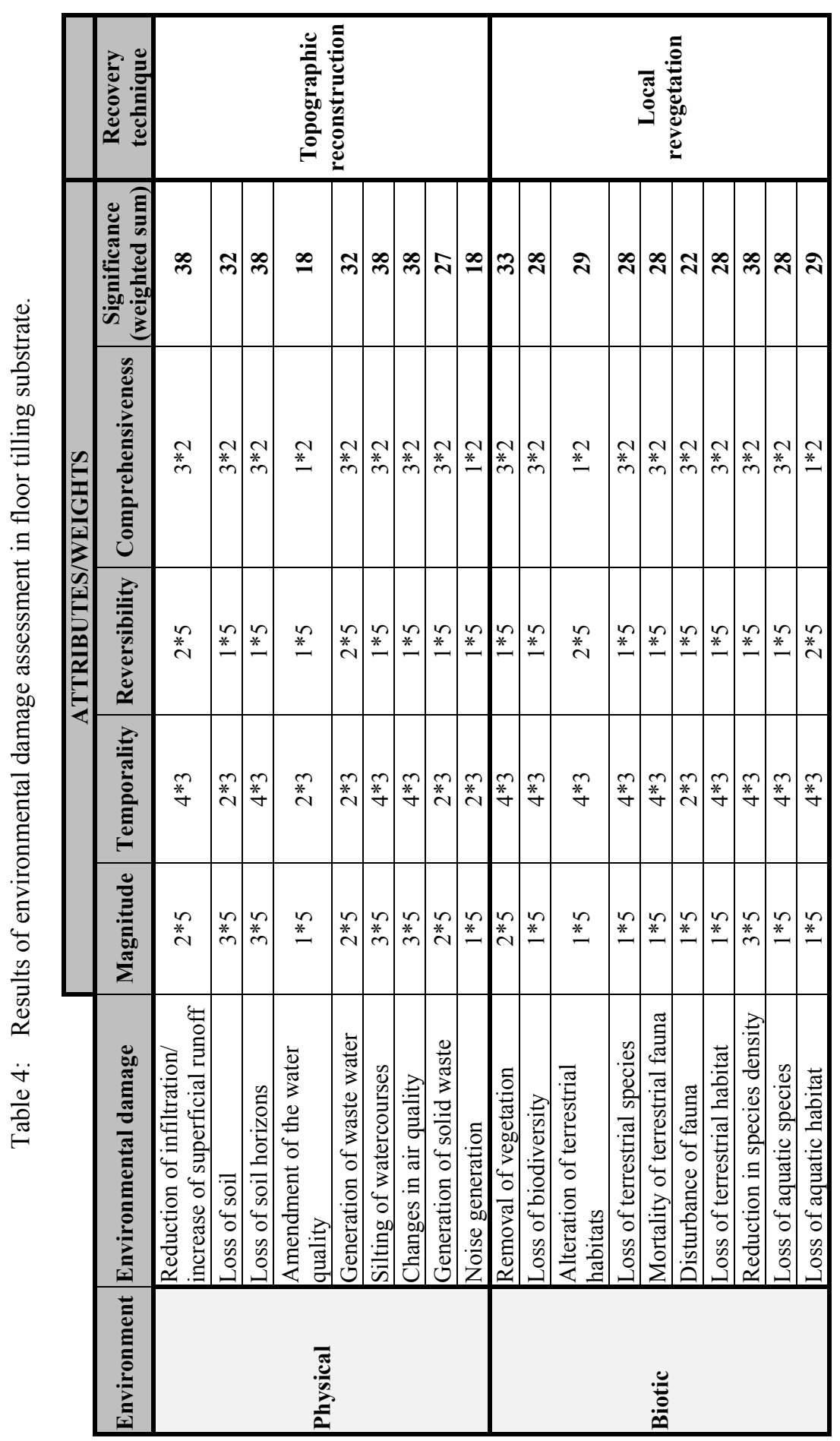


Table 5: Indicated operations to topographic reconstruction.

\begin{tabular}{|l|l|}
\hline \multicolumn{1}{|c|}{ Topographic reconstruction } & \multicolumn{1}{c|}{ Surface preparation } \\
\hline $\begin{array}{l}\text { Bulging or smoothing: Bulge consists of } \\
\text { parts of very uneven terrain that may } \\
\text { compromise the surface preparation for } \\
\text { planting or replanting }\end{array}$ & $\begin{array}{l}\text { Plowing: Operation of cutting, } \\
\text { elevation, inversion and pre- } \\
\text { breakdown of the soil/substrate }\end{array}$ \\
\hline $\begin{array}{l}\text { Terracing: Construction of retaining } \\
\text { structures for the runoff of rain in the } \\
\text { area through terraces }\end{array}$ & $\begin{array}{l}\text { Disking: Operation of desegregation } \\
\text { and levelling of the soil/substrate }\end{array}$ \\
\hline $\begin{array}{l}\text { Slope reconstruction: Process of } \\
\text { smoothing the form of abrupt cuts aimed } \\
\text { at the planting or replanting process }\end{array}$ & $\begin{array}{l}\text { Scarification: Disruption of } \\
\text { compacted layers of subsurface } \\
\text { soil/substrate }\end{array}$ \\
\hline $\begin{array}{l}\text { Removal: Removal of soil material or } \\
\text { substrate for subsequent use in the } \\
\text { planting or replanting process }\end{array}$ & $\begin{array}{l}\text { Subsoiling: Practice of disruption of } \\
\text { the compacted layers at a depth of } \\
\text { 40 cm }\end{array}$ \\
\hline $\begin{array}{l}\text { Transportation: } \text { Translocation of the } \\
\text { substrate at a short considerable distance }\end{array}$ & $\begin{array}{l}\text { Rotary tillage: Operation of tillage/ } \\
\text { substrate using rotary hoes }\end{array}$ \\
\hline $\begin{array}{l}\text { Compression: } \text { The process consists of } \\
\text { compressing the substrates in order to } \\
\text { improve the stability for further planting }\end{array}$ & $\begin{array}{l}\text { Furrowing: Practice of making } \\
\text { furrows in the soil/substrate }\end{array}$ \\
\hline $\begin{array}{l}\text { Creation of drainage channels: Opening } \\
\text { channels to help control local erosion }\end{array}$ & $\begin{array}{l}\text { Pitting process: Drilling holes along } \\
\text { the ground surface/substrate }\end{array}$ \\
\hline $\begin{array}{l}\text { Leveling: Promote systematization of } \\
\text { the area through a pre-established level }\end{array}$ & $\begin{array}{l}\text { Capping of the soil: Assume a given } \\
\text { area on a substrate of interest aimed } \\
\text { at planting }\end{array}$ \\
\hline
\end{tabular}

prepared with two kinds of organic materials (sawdust and manure), easily found in areas adjacent to the National Forest of Jamari.

Green manuring: Green manure is an ancient agricultural practice, which aims to improve the productive capacity of the soil by adding organic material not decomposed, constituting of plants, exclusively grown for this purpose. These plants may or may not be produced in situ and can be used before completing their growth cycle, or even after. From numerous tests in the greenhouse and in the field, four legume species were selected, they showed good growth and adequate dry matter production in these degraded systems: Crotalaria juncea (sunn hemp), Canavalia ensiformis (jack bean), Cajanus cajam (faba bean), and Aterrima mucuna (velvet bean). They are sown in the form of a cocktail party, forming a true "green carpet" surface.

Use of "top soil": The loss of organic matter is a major problem for the recovery of degraded areas in Brazil. The storage and reuse of fertile soil layer ("topsoil") produces excellent results, but most mining companies consider this to be a costly and difficult technique, because this layer is very vulnerable in tropical soils or steep slopes of some soils in many mines. 
Chemical fertilizer and liming: Chemical fertilizers are required for the restoration of degraded soils; a quantity of application must be defined in terms of fertility analysis, and must be performed annually in the first years of management.

Revegetation with native species: The recovery activities aim to allow the succession process in the site that is being worked on, ensuring that all the fundamental factors occur that possibility could or provide the ecosystem successions. Among the critical factors for the development of ecosystem succession in degraded areas is the availability of species, which until recently was seen as just planting seedlings of different species on site.

\section{Conclusions}

The methodology used for assessing environmental damage allowed the definition of the different substrates and recovery actions to be applied on site. The methodology used can be applied to manage areas degraded by mining and other activities with similar levels of damage to the environment components.

The restoration of degraded soils by surface mining depends on a large number of factors, such as texture and structure of soil, slope, length of slope, volume of rainfall in the area, vegetation cover, type and extent of the degree of erosion reached. The technique to be adopted depends on the changing level of human activity in the observed factors.

However, the use of just one technique, such as topographic reconstruction, for example, may not be sufficient to recover the landscape or the environmental quality. The techniques presented have singular objectives, acting in specific components of the environment, at different levels of damage. To recover the soil and the landscape composition, it is necessary to reconstitute the ecosystem characteristics, allowing the succession process to obtain more complex ecosystems. The biological, chemical and physical characteristics from the environment must be re-established in order to provide the degraded site the selfrecover capacity as the activities of recovery cease.

\section{References}

[1] Galbraith, D., Levy, P.E., Sitch, S., Huntingford, C., Cox, P., Williams, M., Meir, P. Multiple mechanisms of Amazonian forest biomass losses in three dynamic global vegetation models under climate change. New Phytologist, 187, pp. 647-665, 2010.

[2] Fearnside, P. What is at stake for Brazilian Amazonia in the climate negotiations? Climatic Change, 118, pp. 509-519, 2013.

[3] Marengo, J , Chou, S., Mourao, C., Solman, S., Sanchez, E., Samuelsson, P., Rocha, R.P., Li, L., Pessacg, N., Remedio, A.R.C., Carril, A.F., Cavalcanti, I.F., Jacob, D. Simulation of rainfall anomalies leading to the 2005 drought in Amazonia using the CLARIS LPB regional climate models. Climate Dynamics, 41, pp. 2937-2955, 2013.

[4] DNPM - National Department of Mineral Production. Economia mineral do Brasil. Brasília: DNPM, 2009 (in Portuguese). 
[5] Townsend, C.R., Begon, M., Harper, J.L. Fundamentos em Ecologia. Porto Alegre: Artmed, 2006 (in Portuguese).

[6] Bertoni, J, Neto, F. L. Conservação do Solo. $5^{\circ}$ Edição, São Paulo: Ícone, 2005 (in Portuguese).

[7] Longo, R.M., Ribeiro, A.I., Melo, W.J. Use of green fertilizing in the recovery of soils degraded by mining in the amazon forest. Bragantia, 70, pp. 139-146, 2011 (in Portuguese).

[8] Filho, C.L.M. Introdução à Geologia de Engenharia. $2^{\circ}$ Edição, Santa Maria: Editora da UFSM; Brasília: Companhia de Pesquisas de Recursos Minerais, 1997 (in Portuguese).

[9] Mafra, N. M. C. Erosão e Planificação de Uso do Solo. In: Guerra, A. J. T., Silva, A. S., Botelho, R. G. M. (Org.). Erosão e Conservação dos Solos. $2^{\circ}$ Edição. Rio de Janeiro: Bertrand Brasil, 2005 (in Portuguese). 